\title{
Sulfur geochemistry of hydrothermal waters in Yellowstone National Park, Wyoming, USA. III. An anion-exchange resin technique for sampling and preservation of sulfoxyanions in natural waters
}

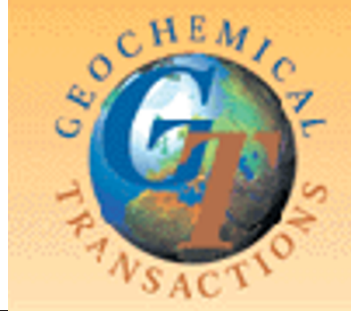

\author{
Greg K. Druschel, ${ }^{a} \dagger$ Martin A. A. Schoonen, ${ }^{a}$ D. Kirk Nordstrom, ${ }^{b}$ James W. Ball, ${ }^{b}$ \\ Yong $\mathrm{Xu}^{c}$ and Corey A. Cohn ${ }^{c}$ \\ ${ }^{a}$ Dept. of Geosciences, State University of New York at Stony Brook, Stony Brook, NY 11794. \\ E-mail: Martin.Schoonen@SUNYSB.edu \\ ${ }^{b}$ U.S. Geological Survey, 3215 Marine Street, Boulder, CO 80303 \\ ${ }^{c}$ Dept. of Geosciences, SUNY at Stony Brook, Stony Brook, NY 11794
}

Received 11th December 2002, Accepted 22nd May 2003

First published as an Advance Article on the web 4th June 2003

\begin{abstract}
A sampling protocol for the retention, extraction, and analysis of sulfoxyanions in hydrothermal waters has been developed in the laboratory and tested at Yellowstone National Park and Green Lake, NY. Initial laboratory testing of the anion-exchange resin Bio-Rad ${ }^{(i x}$ AG1-X8 indicated that the resin was well suited for the sampling, preservation, and extraction of sulfate and thiosulfate. Synthetic solutions containing sulfate and thiosulfate were passed through AG1-X8 resin columns and eluted with 1 and $3 \mathrm{M} \mathrm{KCl}$, respectively. Recovery ranged from 89 to $100 \%$. Comparison of results for water samples collected from five pools in Yellowstone National Park between on-site IC analysis (U.S. Geological Survey mobile lab) and IC analysis of resin-stored sample at SUNY-Stony Brook indicates 96 to 100\% agreement for three pools (Cinder, Cistern, and an unnamed pool near Cistern) and 76 and 63\% agreement for two pools (Sulfur Dust and Frying Pan). Attempts to extract polythionates from the AG1-X8 resin were made using $\mathrm{HCl}$ solutions, but were unsuccessful.

Bio-Rad ${ }^{\circledR}$ AG2-X8, an anion-exchange resin with weaker binding sites than the AG1-X8 resin, is better suited for polythionate extraction. Sulfate and thiosulfate extraction with this resin has been accomplished with $\mathrm{KCl}$ solutions of 0.1 and $0.5 \mathrm{M}$, respectively. Trithionate and tetrathionate can be extracted with $4 \mathrm{M} \mathrm{KCl}$. Higher polythionates can be extracted with $9 \mathrm{M}$ hydrochloric acid. Polythionate concentrations can then be determined directly using ion chromatographic methods, and laboratory results indicate recovery of up to $90 \%$ for synthetic polythionate solutions using AG2-X8 resin columns.
\end{abstract}

\section{Introduction}

Presence of inorganic sulfoxyanions in natural waters

Sulfur is predominantly present as sulfate in aerated waters and as sulfidic sulfur $\left(\mathrm{H}_{2} \mathrm{~S}\right.$ and $\left.\mathrm{HS}^{-}\right)$in anaerobic waters undergoing sulfate reduction. However, in addition to sulfate and sulfidic sulfur, natural waters may also contain some combination of the following: bisulfite $\left(\mathrm{HSO}_{3}{ }^{-}\right)$, sulfite $\left(\mathrm{SO}_{3}{ }^{2-}\right)$, polysulfides $\left(\mathrm{H}_{2-x} \mathrm{~S}_{x}{ }^{-x}\right)$, polythionates $\left(\mathrm{S}_{x} \mathrm{O}_{6}{ }^{2-}\right)$ and thiosulfate $\left(\mathrm{S}_{2} \mathrm{O}_{3}{ }^{2-}\right)$. These species are sometimes collectively referred to as intermediate sulfur species (ISS) because the average oxidation state of sulfur in these species is between that of sulfidic-sulfur $(-\mathrm{II})$ and that of sulfate-sulfur $(\mathrm{VI}) .^{1,2}$ Except for the polysulfide species all other ISS are sulfoxyanions. On the basis of equilibrium speciation calculations, the concentration of none of the sulfoxyanions is expected to be higher than $0.01 \%$ of the total dissolved sulfur concentration, $S_{\text {tot. }}{ }^{1}$ Hence, if $10^{-2}$ molals are taken as a reasonable upper limit for the concentration of total dissolved sulfur in most fresh waters and hydrothermal waters, ${ }^{3}$ none of the sulfoxyanions are expected to have concentrations over $1 \mu \mathrm{M}$.

However, several studies have reported sulfoxyanion concentrations well in excess of $1 \mu \mathrm{M}$. For example, thiosulfate

$\dagger$ Present address: College of Marine Studies, University of Delaware, 700 Pilottown Road, Lewes, DE 19958. E-mail: druschel@udel.edu in three brines collected from the French Dogger Formation ranged in concentration from 100 to $200 \mu \mathrm{M}$ ( $S_{\text {tot }}$ ranged from 6.88 to $7.3 \mathrm{mM}){ }^{4}$ Thiosulfate concentrations of 705 to $875 \mu \mathrm{M}$ were reported for Champagne Pool, New Zealand $\left(S_{\text {tot }}=2.5 \times 10^{-3} \mathrm{M}\right){ }^{5,6}$ A survey of twenty-seven Bulgarian hydrothermal waters found thiosulfate concentrations ranging from 5 to $38 \mu \mathrm{M}$ along with sulfite concentrations ranging from 5 to $20 \mu \mathrm{M}$ for waters with $S_{\text {tot }}$ less than $3100 \mu \mathrm{M}$. ${ }^{7}$ Thiosulfate concentrations up to $36 \mu \mathrm{mol} \mathrm{L}{ }^{-1}$ were found in several Italian hot springs with sulfide-bearing waters with a $S_{\text {tot }}$ of around $12 \mathrm{mmol} \mathrm{L}^{-1.8}$ In an extensive survey of the hot springs of Yellowstone National Park, Allen and Day ${ }^{9,10}$ reported thiosulfate concentrations for several alkaline hot-spring waters. For example, a thiosulfate concentration of $45 \mu \mathrm{M}$ for Ojo Caliente which has a $S_{\text {tot }}$ of about $250 \mu \mathrm{M}$ was reported. $\mathrm{Xu}$ et al. ${ }^{11,12}$ determined thiosulfate in about 40 hot-spring waters in Yellowstone National Park. They found elevated sulfoxyanion concentrations in several pools, including a thiosulfate concentration in Azure Spring at about $20 \mathrm{~mol} \%$ of $S_{\text {tot }}$ and tens of $\mu$ molar concentrations of polythionate in Cinder Pool. ${ }^{11,12}$

High polythionate concentrations are often found in acid crater lakes associated with active volcanoes and some acid hot springs. A high total polythionate concentration of $113 \mu \mathrm{M}$ (average $n=5.5, S_{\text {tot }}=3.1 \times 10^{-3} \mathrm{M}$ ) was found in a sample taken from Ketetahi Cauldron, Tongariro National Park, New Zealand. ${ }^{6}$ For Ruapehu Crater Lake, New Zealand, 
Takano et al. ${ }^{13}$ reported an extensive survey of polythionate concentrations. Some of the samples contained considerable amounts of polythionates. For example, sample R18F collected at Ruapehu Crater Lake contained $1.95 \mathrm{mM} \mathrm{S}_{4} \mathrm{O}_{6}{ }^{2-}, 2.1 \mathrm{mM}$ $\mathrm{S}_{5} \mathrm{O}_{6}{ }^{2-}$, and $0.82 \mathrm{mM} \mathrm{S}_{6} \mathrm{O}_{6}{ }^{2-}$. The total amount of $\mathrm{S}$ represented by these three polythionates accounts for $12 \%$ of the total dissolved sulfur in this water. There are more studies that report sulfoxyanion concentrations than summarized here, but none of these other studies provide enough data to evaluate the abundance of sulfoxyanions in relation to the total sulfur in these waters. ${ }^{14,15}$

Hence, there are a number of studies that suggest sulfoxyanions persist at higher concentrations in various types of natural waters than expected based on equilibrium thermodynamics. The occurrence of non-equilibrium concentrations of sulfoxyanions in natural waters is likely to result from sluggish and often incomplete redox reactions involving hydrogen sulfide, sulfur dioxide, or sulfate. The two most important redox processes in which sulfoxyanions form are the oxidation of hydrogen sulfide and the reduction of sulfate. Oxidation of hydrogen sulfide in $\mathrm{O}_{2}$-bearing waters proceeds via the formation of thiosulfate and elemental sulfur as demonstrated in several laboratory studies ${ }^{16-18}$ and field studies. ${ }^{12,18-21}$ Oxidation of thiosulfate in the presence of pyrite or other metal sulfides leads to the formation of tetrathionate. ${ }^{22,23}$ This process has been documented to occur in Cinder Pool, Yellowstone National Park. ${ }^{11}$ Reduction of sulfate proceeds via microbial pathways ${ }^{24-27}$ via poorly understood mechanisms. ${ }^{28-31}$ Sulfidic sulfur is typically the main product of microbial sulfate reduction but thiosulfate is also formed in sediments and acts as a link between sulfate reduction and hydrogen sulfide oxidation in sediments. ${ }^{32,33}$ Thermochemical sulfate reduction yields elemental sulfur as well as hydrogen sulfide. Interaction of sulfidic water with elemental sulfur can lead to waters with a high thiosulfate concentration. ${ }^{11}$ Incomplete oxidation of $\mathrm{SO}_{2}$ may play a role in the ISS distribution in crater lakes on active volcanoes. ${ }^{34-36}$ Releases of magmatic $\mathrm{SO}_{2}$ gas in a crater lake can lead to complex sulfur speciation dominated by sulfate with polythionates as a minor species. Many acid crater lakes are underlain by a pool of molten sulfur which interacts with the crater-lake water to produce a complex sulfur speciation that includes polythionates. Thus, monitoring of ISS in crater lakes may be a viable method to characterize changes in $\mathrm{SO}_{2}$ release, an important indicator of potential volcanic activity. ${ }^{35,37}$

The presence and persistence of sulfoxyanions in natural waters is potentially of importance in several other processes. Sulfoxyanions may play a role in the transport of metals. Experimental studies suggest that sulfite and thiosulfate form stable complexes with gold and silver. ${ }^{38-42}$ Hence, if the concentration of these oxyanions is significant they may account for some of the mobility of gold and silver in natural waters. Sulfoxyanions are also thought to play an important role in the isotopic equilibration of sulfate-sulfur and sulfidic-sulfur. The isotopic equilibration of sulfate-sulfur and sulfidic-sulfur in a hydrothermal system must proceed via a sequence of reactions where a sulfur(VI) species is reduced to a sulfur(-II) species and vice versa. ${ }^{43}$ One such scheme involves the formation of thiosulfate. ${ }^{44}$ Finally, many microorganisms can use thiosulfate and polythionates as an energy source during oxidation or reduction. ${ }^{33,45-47}$

\section{Sampling and analysis of dissolved $\mathbf{S}$ species in natural waters}

Given the geochemical importance of dissolved sulfide, sulfate, and the potential importance of sulfoxyanions in natural water, it is important to be able to determine the sulfur speciation in a wide range of natural solutions. In the last two decades, several studies have been published presenting analytical methods for the determination of sulfidic sulfur, ${ }^{48,49}$ sulfur oxyanions, ${ }^{1,50-52}$ sulfur oxyanions and sulfide species, ${ }^{6,7,53-56}$ as well as inorganic $\mathrm{S}$-species and thiols ${ }^{57}$ in natural waters and waste waters. Analytical schemes for the determination of complete or nearly complete sulfur speciation in aliquots withdrawn from $\mathrm{H}_{2} \mathrm{~S}$ oxidation experiments have been presented in several studies. ${ }^{16-18}$ In addition, several papers have discussed the general problems in sampling and preserving unstable (i.e., volatile or reactive) constituents in natural waters. ${ }^{58,59}$

The sampling, preservation and analysis of sulfur species in spring waters and hot spring waters presents a major challenge because the discharging water is often far from equilibrium with the atmosphere. Upon discharge, processes such as degassing (e.g., $\mathrm{CO}_{2}, \mathrm{H}_{2} \mathrm{~S}$ ), mineral precipitation (e.g., $\left.\mathrm{BaSO}_{4}, \mathrm{CaCO}_{3}\right)$, and oxidation $\left(\mathrm{H}_{2} \mathrm{~S}\right)$ may drastically change the chemical composition, including the sulfur speciation, of the water. ${ }^{60}$ Most of these processes proceed even after a sample has been collected and sealed in a bottle. Hence, either the analyses have to be conducted immediately after collection of the sample, which is often impractical, or the sample must be preserved so that later analysis is meaningful. Several studies have evaluated the effect of prolonged storage on preserved, sealed samples. ${ }^{5,13}$ The results by Webster ${ }^{6}$ indicate that the thiosulfate concentration obtained after about one hour is the same as for duplicate sealed samples analyzed after 2, 3, 4, 9 and 13 days. However, the $\mathrm{H}_{2} \mathrm{~S}$ content of the duplicates decreased with storage; after 13 days only a small fraction of the initial $\mathrm{H}_{2} \mathrm{~S}$ was recovered. Takano et al. ${ }^{13}$ analyzed several duplicate samples for polythionates in which one duplicate had been opened previously for analysis and resealed and the other sample had never been opened. Except for one pair of samples, the result showed that there was no significant difference in polythionate composition and concentration between the duplicates. However, for logistical reasons, neither of the studies were able to evaluate changes on a time scale of minutes to an hour after sampling.

\section{Previous studies using resins to determine dissolved sulfur species}

Resins have been used before in the field and laboratory to concentrate dissolved ionic constituents ${ }^{61-63}$ and sequester redox species (e.g., As(III $\left.)^{64}\right)$. Resins capable of retaining anions have been used in the past to separate sulfoxyanions, sulfide and sulfate from waste waters and ground waters. ${ }^{65-69}$ In all these prior studies, the resin was used to sequester the dissolved species, followed by a sequential elution to allow for the analyses of the different types of sulfur species. In one study an anion exchange resin was used to remove dissolved sulfide from an alkaline groundwater. ${ }^{70}$

\section{Present study objectives}

The primary objective in this study was to evaluate the use of anionic resins to sequester sulfur oxyanions from hydrothermal solutions and crater lakes. Field tests and laboratory experiments were conducted to evaluate the technique. In addition the technique was used in the determination of the sulfur species of a stratified lake with high dissolved sulfide and sulfate concentrations. Subsequent field studies in Yellowstone National Park and a field study of the hydrothermal springs in Lassen Volcanic National Park using the technique presented in this paper will be published separately.

\section{Methods}

\section{Selection of resin}

The selection of a resin is dictated by the objectives of the application. In this study the primary objective was to sequester the sulfoxyanions from a hydrothermal solution and subsequently elute these species, followed by analysis using ion chromatography (IC). The selectivity of an anion resin is 
governed by the type of functional groups present on the resin. Anionic resins, such as the ones used in this study (Bio-Rad ${ }^{(i i)}$ AG), consist of a styrene divinylbenzene copolymer lattice with quaternary ammonium functional groups saturated with counter ions. ${ }^{63}$ Ion exchange takes place at the functional groups if the resin is exposed to a solution that contains anions for which the functional groups have a higher selectivity than the counter ions. Most anion exchange resins are sold with chloride as the counter ion (Cl-form). Through exchange it is possible to change the composition of the counter ion; for example, a resin can be converted from the $\mathrm{Cl}$-form to the $\mathrm{OH}$ form. ${ }^{71}$ The chloride form of these resins exhibits a significantly better resistance to high temperature (up to $150{ }^{\circ} \mathrm{C}$ ) applications (Bio-Rad, 1999) than the OH-form. Hence, the Cl-form was used in this study because of the high temperature of the waters studied, but for some applications it may be advantageous to convert the resin to, for example, the $\mathrm{OH}$-form.

Two types of AG resins, the Bio-Rad ${ }^{(} \mathrm{AG} 1-\mathrm{X} 8$ and AG2$\mathrm{X} 8$, both sold in the $\mathrm{Cl}$-form, were evaluated in this study. These two resins are analytical-grade Dowex anion exchange resins with the same styrene divinylbenzene copolymer lattice. The percentage of cross-linking in the copolymer lattice controls its porosity. A high porosity allows large molecules, such as proteins and antibodies, to penetrate the resin and exchange, whereas a low porosity excludes large molecules from exchanging with the resin. The two resins used in this study are $8 \%$ cross linked and are particularly suitable for the exchange of inorganic anions. ${ }^{71}$ The resins differ, however, in the composition of the functional groups $(\mathrm{AG} 2-\mathrm{X} 8$ replaces a $\mathrm{CH}_{3}$ group with a $\mathrm{C}_{2} \mathrm{H}_{4}(\mathrm{OH})$ group in the $\mathrm{R}-\mathrm{CH}_{2} \mathrm{~N}^{+}\left(\mathrm{CH}_{3}\right)_{3}$ of the AG1-X8 resin) which affects the relative selectivity of the resins.

The relative selectivity of a sample ion with respect to the counterion determines how strongly, if at all, a sample ion will bind to the resin (Table 1). The counterions are only exchanged with ions of like charge, therefore oppositely charged or neutral species will not be retained on the counterion sites. Hence, dissolved $\mathrm{H}_{2} \mathrm{~S}, \mathrm{O}_{2}$, and potentially reactive transition metals will not be retained on these sites. Though neutral species may be retained to some degree in a resin through a process which forms the basis for ion-exclusion chromatography, it is reasonable to expect separation of neutral and ionic species. As noted above it has been our experience that the presence of these two constituents in a sample changes the sulfoxyanion speciation upon storage. Therefore, sequestering the sulfoxyanions on a resin and separating these species from $\mathrm{H}_{2} \mathrm{~S}, \mathrm{O}_{2}$, and transition metal-bearing solutions (by loading the resin and flushing with deoxygenated water) avoids this problem. Chloride counterions are replaced by anions in the sample with greater selectivity (see Table 1). An AG1-X8 resin in the chloride form, for example, would not exchange $\mathrm{HCO}_{3}{ }^{-}$ (selectivity $=1.2$ ) for the counterion $\mathrm{Cl}^{-}$(selectivity 2.3), but would readily exchange $\mathrm{HSO}_{4}{ }^{-}$(selectivity $=15$ ). Elution of anions held on the resin requires application of a gradient of $\mathrm{Cl}^{-}$ions proportional to its selectivity on the resin. The anions with higher selectivity, therefore, require a greater concentration of $\mathrm{Cl}^{-}$ions applied to the resin to be extracted from the binding sites on the resin's polymer structure.

The AG2-X8 resin is a less basic, and therefore less selective,

Table 1 Relevant selectivities of anion exhange resins used in this study

\begin{tabular}{lll}
\hline & \multicolumn{2}{l}{ Selectivity with respect to $\mathrm{OH}^{-}$} \\
\cline { 2 - 3 } Ion & $\mathrm{AG} 1-\mathrm{X} 8$ & $\mathrm{AG} 2-\mathrm{X} 8$ \\
\hline $\mathrm{Cl}^{-}{ }^{2-} \mathrm{HSO}_{4}{ }^{-}$ & 22 & 2.3 \\
$\mathrm{SO}_{4}{ }^{2-}$ & 85 & 15 \\
$\mathrm{~S}_{2} \mathrm{O}_{3}{ }^{2-}$ & $\approx 275$ & $\approx 90$ \\
$\mathrm{~S}_{x} \mathrm{O}_{6}{ }^{2-}(n>2)$ & Fully retained & $\approx 500$ \\
\hline
\end{tabular}

resin than the AG1-X8 resin (see Table 1; data from Bio-Rad and this study). The AG2-X8 resin exhibits binding capacities approximately 10 times weaker than the AG1-X8 resin. Ions of higher selectivity that may not be eluted from the AG1-X8 resin, may, therefore, be extracted from the AG2-X8 resin. For example, polythionates are fully retained on the AG1-X8 resin and cannot be eluted, even with $9 \mathrm{~N} \mathrm{HCl}$ as eluent. However, polythionates can be eluted from the AG2-X8 resin (Table 1).

\section{Column preparation}

Bio-Rad $^{(m)}$ Anion-exchange resins AG1-X8 and AG2-X8 (both 100-200 mesh size, chloride form), with a $1.2 \mathrm{meq} \mathrm{ml}^{-1}$ capacity were used in laboratory experiments and field experiments. Both the Bio-Rad ${ }^{(i x}$ AG1-X8 and AG2-X8 resins were obtained in loose form, and were packed in columns of desired length before use. Columns were prepared (see Fig. 1) by cutting pre-made columns of approximately $2 \mathrm{~cm}$ diameter to the desired length, and filled with an appropriate volume of resin (Bio-Rad ${ }^{\text {(iin }}$ resin columns are conveniently marked in $\mathrm{ml}$ increments).

To fill the column with resin, a polyethylene frit was inserted into the bottom, and a slurry of the resin (prepared using nanopure water, resistance $>18 \mathrm{M} \Omega$ ) was poured in. The water was allowed to drip out of the open end, compacting the saturated resin in the column. No air pockets should form in the resin, and the column was re-packed upon observation of any empty spaces. Another frit was inserted onto the top of the resin and a male tubing connector wrapped with Teflon ${ }^{(i 0}$ tape was snugly inserted into the column. The packed column was then flushed with nanopure water through a syringe and connecting tubing, and sealed with plastic caps. The all-plastic construction of the columns is well-suited for fieldwork and shipping.

Depending on the sample size and expected analyte concentration, it is important to ensure that there will be enough resin to retain equivalent anions in the sample. Bio-Rad ${ }^{(i x}$ AG1-X8 and AG2-X8 resins are listed with a binding capacity of $1.2 \mathrm{meq} 1^{-1}$. As with any analytical technique, care should be exercised that this value is accurate. The volume of resin used to sample any quantity of sample should be chosen so as to ensure that there will be an excess of available sites. Exceeding the capacity of the resin will result in incomplete capture of ions and lowered efficiency of the method.

\section{Sampling}

All laboratory and field samples were collected in 5-60 ml sterile plastic syringes and pressed through a $0.45 \mu \mathrm{m}$ syringe filter before passing the solution through the prepared exchange resin columns. To improve the interaction between the sample ion and resin, the flow rate did not exceed $3 \mathrm{~mL}$ min $^{-1}$ (which can be measured by timing how fast a graduated cylinder or falcon tube is filled). In preliminary lab experiments we found that at higher flow rates the sample ions are not always fully retained, presumably due to the shorter contact time. The volume of each sample was carefully measured by
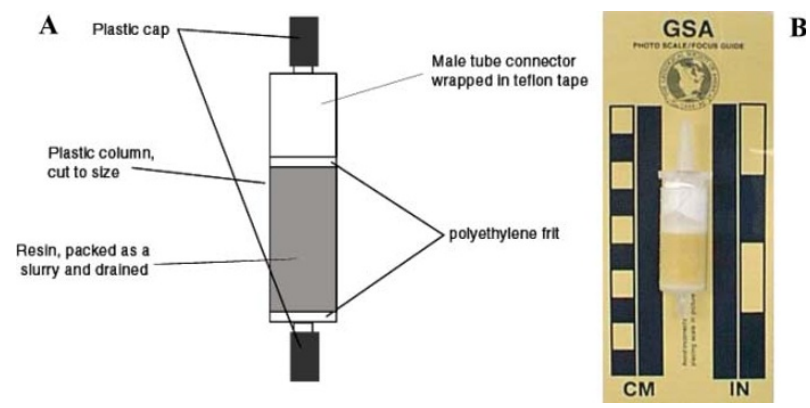

Fig. 1 A: Schematic of resin column; B: picture. 
collecting the effluent in a volumetric flask of appropriate size. In all laboratory experiments, the sample solution passed through the columns was collected and analyzed for sulfoxyanions to evaluate whether these species were completely retained on the column. These results indicated that the resin retained all of the sulfoxyanions of interest. After the desired volume of sample had been passed through the column, $30-40 \mathrm{ml}$ of nanopure water were passed through the column to displace any remaining sample solution. This step is important because it removes residual $\mathrm{H}_{2} \mathrm{~S}$ dissolved in the sample fluid. After flushing, the column was capped, shipped, and stored until elution of the retained species could be carried out.

\section{Elution}

Sequential elutions from the AG2-X8 with $0.1 \mathrm{M} \mathrm{KCl}, 0.5 \mathrm{M}$ $\mathrm{KCl}$, and $4 \mathrm{M} \mathrm{KCl}$ were carried out to remove $\mathrm{SO}_{4}{ }^{2-}, \mathrm{S}_{2} \mathrm{O}_{3}{ }^{2-}$, and $\mathrm{S}_{x} \mathrm{O}_{6}{ }^{2-}$, respectively (Fig. 2). Sequential elutions for the AG1-X8 resin were additionally made with 1 and $3 \mathrm{M} \mathrm{KCl}$ solutions. $\mathrm{KCl}$ eluents were made from reagent grade $\mathrm{KCl}$ salt and $18 \mathrm{M} \Omega$ water. A peristaltic pump with Tygon ${ }^{(i)}$ tubing was used to pass each eluent through the columns at a flow rate between 0.75 and $2.0 \mathrm{ml} \mathrm{min}{ }^{-1}$. Total sample recovery was found to be independent of flow rate, but the ability to concentrate analyte in smaller volume aliquots was found to be affected by flow rates due to dispersion of the analyte breakthrough curve.

Elution of a column must begin with the lowest eluent concentration $(0.1 \mathrm{M} \mathrm{KCl})$ for elution of the $\mathrm{SO}_{4}{ }^{2-}$ while leaving the other sulfoxyanions on the column. Elution for thiosulfate utilizes a $0.5 \mathrm{M} \mathrm{KCl}$ solution. Elution for polythionates can be accomplished with a $4 \mathrm{M} \mathrm{KCl}$ eluent acidified to $0.01 \mathrm{M} \mathrm{HCl}$ for better preservation of the polythionates as they are eluted. $9 \mathrm{M} \mathrm{HCl}$ was also used as an eluent for polythionate extraction (from ACS reagent grade $35 \% \mathrm{HCl}$ ). Each eluted aliquot was weighed by difference using a Mettler ${ }^{\text {(ii }}$ toploading balance. Samples were diluted by weight on a Mettler ${ }^{(i x}$ analytical balance in the IC autosampler vials and thoroughly mixed by inversion before analysis.

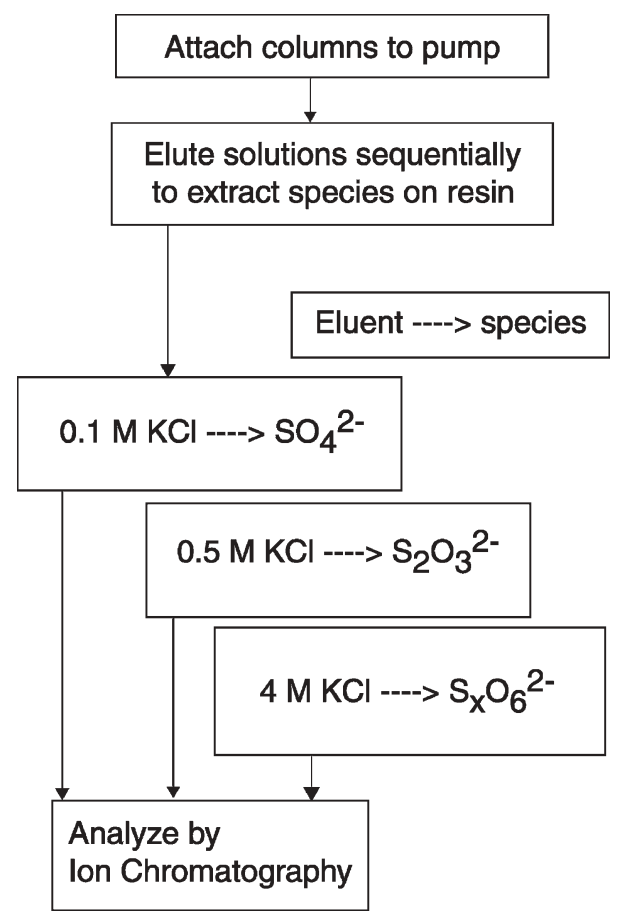

Fig. 2 Flow chart of resin column extraction process, where $\mathrm{S}_{x} \mathrm{O}_{6}{ }^{2-}$ is the total concentration of all polythionates in a sample.

\section{Analysis}

Eluted aliquots were analyzed using an isocratic elution with a concentrated sodium bicarbonate-sodium carbonate eluent over a run time of 15 minutes with a Dionex ${ }^{(i m}$ DX-500 Ion Chromatography system (ED40 electrochemical detector, GP50 gradient pump, and AS40 Autosampler), employing an AS4A-SC analytical column. Data collection, standardization, and chromatograph manipulation were accomplished using the Dionex PeakNet 5.1 software package. The $18 \mathrm{mM} \mathrm{CO}_{3}{ }^{2-}$ / $28 \mathrm{mM} \mathrm{HCO}_{3}{ }^{-}$eluent was prepared from the Fischer Scientific analytical grade $\mathrm{Na}$-salts. Polythionates were detected with the same IC system using an isocratic $30 \%$ acetonitrile : $\mathrm{H}_{2} \mathrm{O}$ eluent containing $2 \mathrm{mN}$ tetrabutylammonium hydroxide, buffered with $3 \mathrm{mM} \mathrm{NaHCO} / 3 \mathrm{mM} \mathrm{Na} \mathrm{CO}_{3}$ and run through an IonPac NS1 column. The method was modified from Zou et $a .^{72}$ Tri-, tetra-, and pentathionate were all resolvable down to $5 \mu \mathrm{M}$ concentrations using a $25 \mu \mathrm{l}$ sample loop and either conductivity detection or UV detection at $215 \mathrm{~nm}$. Stock solutions containing $\mathrm{SO}_{4}{ }^{2-}, \mathrm{S}_{2} \mathrm{O}_{3}{ }^{2-}$, and $\mathrm{S}_{4} \mathrm{O}_{6}{ }^{2-}$ were prepared from analytical grade sodium salts of each. Sodium trithionate salts were synthesized after the method in Kelly and Wood ${ }^{73}$ utilizing the reaction of thiosulfate with hydrogen peroxide. Purity of the trithionate salt was determined by gravimetry and chromatographic analyses to be greater than $99 \%$. These stock solutions were diluted to yield a series of standards. The standards were matrix-matched to $0.1 \mathrm{M} \mathrm{KCl}$. All standards and samples were analyzed in triplicate for each run, with check standards between every fifth sample (all check standards were analyzed to at least $95 \%$ consistency compared to other standards).

The sulfoxyanion concentration in the original solution loaded onto the column is calculated in four steps. First the concentration of the sulfoxyanions in each of the eluted fractions is calculated by correcting for any dilution that was necessary to analyze the fraction. The concentrations are expressed in moles per kilogram of solution. Secondly, the actual number of moles eluted is calculated by dividing the concentration calculated in step one by the mass of the fraction $(\mathrm{kg})$. The number of moles of each species is then summed over all eluted fractions for a given column. That sum is divided by the sample mass that was passed through the column to yield the concentration of each species in the original solution.

\section{Field tests}

Field tests of the AG1-X8 and AG2-X8 resins were conducted in Yellowstone National Park during the summers of 1997 and 1998. These tests consisted of comparing on-site analyses of sulfoxyanions with analyses of sulfoxyanions eluted from resin columns. The resin columns were loaded at the same time water samples were collected for on-site analyses. The on-site analyses were carried out in a mobile lab equipped with a Dionex 2010I IC. The mobile lab, operated and maintained by the USGS, was parked as close as possible to the hot springs used for the tests (from several meters to several hundred meters away depending on specific location). Procedures for the collection of water samples in Yellowstone National Park and on-site analyses of sulfoxyanions as well as total dissolved sulfide have been described in earlier papers. ${ }^{12,60}$ On-site analysis of $\mathrm{H}_{2} \mathrm{~S}$ was accomplished using a Hach DR-2000 portable spectrophotometer and a standard colorimetric method (Hach method \#8131). Loaded resin samples were collected and transported back to the laboratory where they were analyzed from several days to several weeks after initial collection.

\section{Results and discussion}

For several years our research team has attempted to develop a sampling strategy that involved the use of additives to stabilize 
Table 2 Stability of polythionate and thiosulfate in samples from Cinder Pool, YNP

\begin{tabular}{|c|c|c|c|c|c|c|c|}
\hline \multirow[b]{2}{*}{ Sample } & \multirow[b]{2}{*}{ Treatment } & \multicolumn{3}{|l|}{$\mathrm{S}_{2} \mathrm{O}_{3}{ }^{2-} / \mu \mathrm{M}$} & \multicolumn{3}{|l|}{$\mathrm{SCN}^{-} / \mu \mathrm{M}$} \\
\hline & & Field, 8/23/95 & Lab, 9/21/95 & $\mathrm{Lab}, 7 / 20 / 96$ & Field, 8/23/95 & Lab, 9/21/95 & Lab, 7/20/96 \\
\hline $\mathrm{S}_{2} \mathrm{O}_{3}$ & Standard ${ }^{a}$ & 21.2 & 20.6 & 19.0 & & & \\
\hline $\mathrm{SCN}$ & Standard & & & & 9.2 & 9.5 & 9.3 \\
\hline $\mathrm{SCN}$ & Standard & & & & 3.5 & 3.6 & 3.7 \\
\hline CD-2 & None & 45.0 & 17.1 & 6.2 & & & \\
\hline CD-2 & $\mathrm{KCN}$ & 53.2 & 52.0 & 60.3 & 11.1 & 14.1 & 19.9 \\
\hline CD-3 & None & 43.5 & 11.7 & 10.4 & & & \\
\hline CD-3 & $\mathrm{ZnCl}_{2}$ & 43.8 & 48.2 & 50.0 & & & \\
\hline CD-3 & $\mathrm{KCN}$ & 48.9 & 52.1 & 51.9 & 5.7 & 12.5 & 11.4 \\
\hline CD-4 & None & 42.9 & 16.19 & 7.6 & & & \\
\hline CD-4 & $\mathrm{ZnCl}_{2}$ & 42.8 & 46.1 & 48.3 & & & \\
\hline CD-4 & $\mathrm{KCN}$ & 45.5 & 48.3 & 52.4 & 4.1 & 11.5 & 12.1 \\
\hline
\end{tabular}

thiosulfate in hot-spring waters ${ }^{23}$ and sulfide-rich ground waters. ${ }^{60}$ For example, we experimented with adding zinc or cadmium chloride to water sample to quantitatively remove dissolved sulfide and preserve polythionates and thiosulfate. The expectation was that this would prevent the formation of thiosulfate and polythionates as a result of sulfide oxidation. However, studies of the stability of samples taken at Cinder Pool and Ojo Caliente, Yellowstone National Park, showed that the sulfoxyanion speciation changed over time (Table 2). Results from a study of samples taken at Cinder Pool showed that the concentrations of thiosulfate and polythionates changed over a time scale of weeks to months. We have also found that the thiosulfate concentration can change within minutes after sampling. In a field test at Ojo Caliente, Yellowstone National Park, two samples were taken. To one sample a $\mathrm{CdCl}_{2}$ solution was added, while the other sample was left untreated (Fig. 3). Immediately after collection (and $\mathrm{CdCl}_{2}$ addition), both samples were cooled by placing the bottles in ice water. Both samples were analyzed within 10 minutes after sampling using an IC in the mobile lab. The analysis was repeated after five minutes. We found that in the presence of $\mathrm{Cd}$ the thiosulfate concentration was higher than the untreated sample, and appeared to increase somewhat over time, whereas the untreated sample gave the same concentration for both analyses. Problems such as these spurred the development of this resin technique.

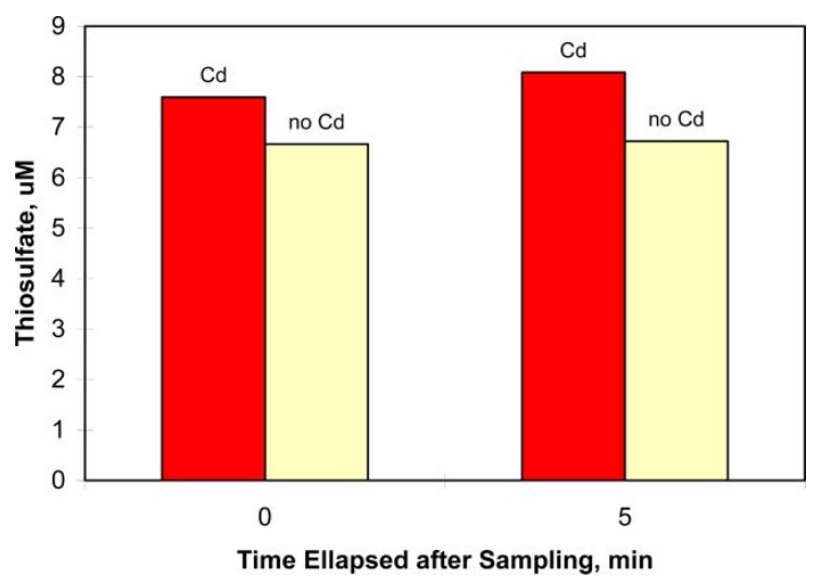

Fig. 3 Effect of addition of $\mathrm{Cd}$ on thiosulfate concentration. Test conducted at Ojo Caliente, YNP. $0.5 \mathrm{~mL} 0.5 \mathrm{M} \mathrm{Cd}$ acetate was added to $60 \mathrm{~mL}$ sample. Analysis were conducted on site using a mobile lab parked next to the spring.

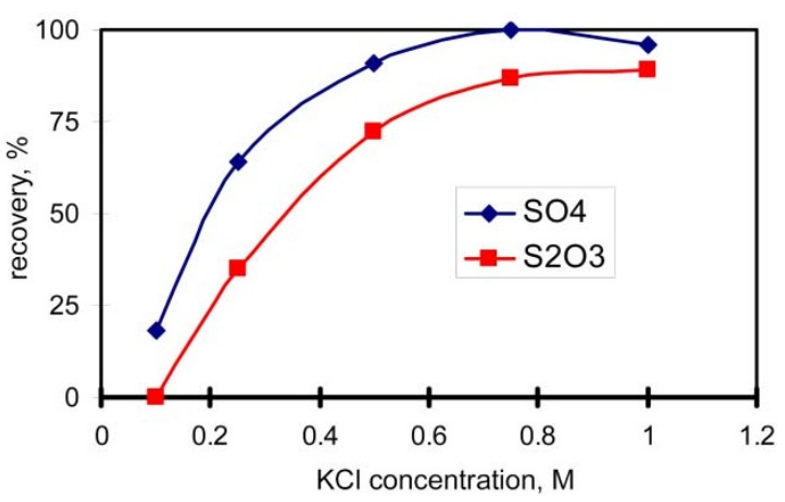

Fig. 4 Recovery of sulfate and thiosulfate from a synthetic solution loaded on AG1-X8 resin column as a function of eluent $(\mathrm{KCl})$ concentration.

\section{Laboratory experiments}

AG1-X8 resins were tested in the laboratory using $\mathrm{SO}_{4}{ }^{2-}$ and $\mathrm{S}_{2} \mathrm{O}_{3}{ }^{2-}$ eluted with varying concentrations of eluents. The results (Fig. 4) indicate the eluent concentrations most effective for extracting of $\mathrm{SO}_{4}{ }^{2-}$, and $\mathrm{S}_{2} \mathrm{O}_{3}{ }^{2-}$ are 1 and $3 \mathrm{M} \mathrm{KCl}$ solutions. Recovery of these two species from the resin was between 89 and $100 \%$. Several eluents were also tested for eluting $\mathrm{S}_{x} \mathrm{O}_{6}{ }^{2-}$ from the AG1-X8 resin, including $6 \mathrm{M} \mathrm{HCl}, 9 \mathrm{M} \mathrm{HCl}$, $12 \mathrm{M} \mathrm{HCl}$, and $6 \mathrm{~N} \mathrm{H}_{2} \mathrm{SO}_{4}$ without success.

$\mathrm{AG} 2-\mathrm{X} 8$ resins were tested in the laboratory using $\mathrm{SO}_{4}{ }^{2-}$, $\mathrm{S}_{2} \mathrm{O}_{3}{ }^{2-}$, and $\mathrm{S}_{4} \mathrm{O}_{6}{ }^{2}$. Several test solutions were formulated to represent hydrothermal solutions from circumneutral to extremely acidic (down to a $\mathrm{pH}$ of approximately 0.5 ) conditions over a range of temperatures $\left(20-75{ }^{\circ} \mathrm{C}\right)$. Resin performance was not noticeably affected by any changes in temperature or acidity. Eluents of 0.1 and $0.5 \mathrm{M} \mathrm{KCl}$ were found to be efficient in the extraction of $\mathrm{SO}_{4}{ }^{2-}$, and $\mathrm{S}_{2} \mathrm{O}_{3}{ }^{2-}$ from the resin column, respectively. Recovery of these two species from the resin was between 90 and $100 \%$ in laboratory tests.

The detection limit of thiosulfate in natural waters can be significantly reduced by increasing the ratio of sample size to aliquot size. By concentrating a majority of the thiosulfate in one or two aliquots of $20-40 \mathrm{ml}$ volume, the sample can be preconcentrated before analysis by IC. For example, if $1000 \mathrm{~mL}$ of a solution containing $1 \mu \mathrm{mol} \mathrm{L}{ }^{-1} \mathrm{~S}_{2} \mathrm{O}_{3}{ }^{2-}$ is loaded on a resin column and all the thiosulfate is eluted in $40 \mathrm{~mL}$, the thiosulfate concentration in this fraction will be $25 \mu \mathrm{mol} \mathrm{L}{ }^{-1}$.

Several concentrations of $\mathrm{HCl}$ were tested to determine the 

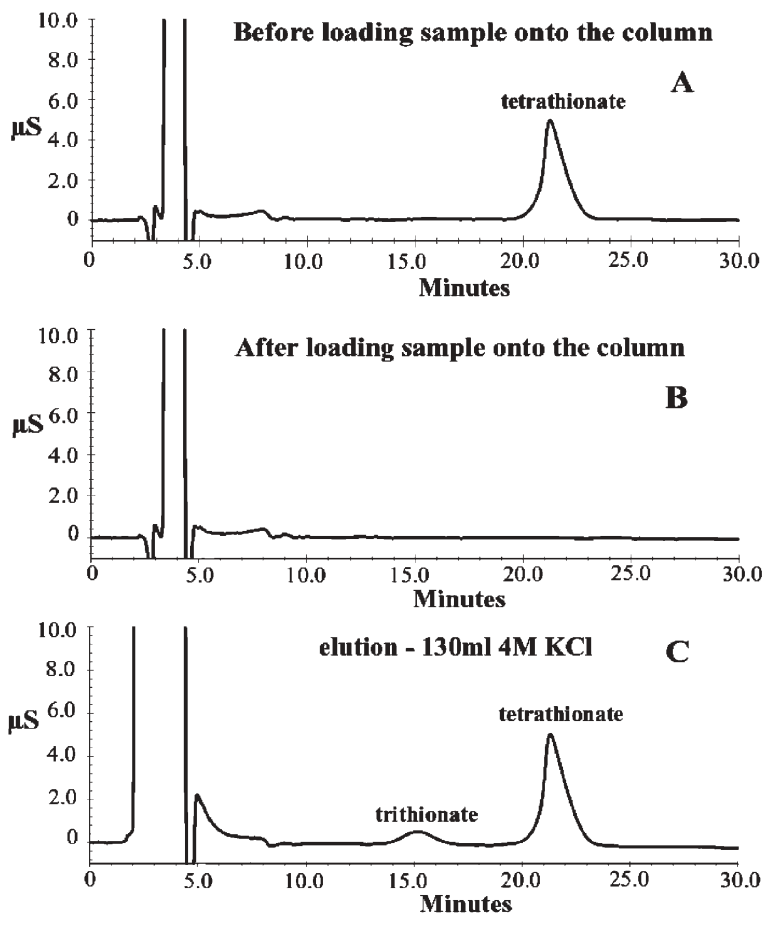

Fig. 5 Results of AG2-X8 resin elution with $4 \mathrm{M} \mathrm{KCl} \mathrm{elution.}$

lowest concentration effective for extraction of $\mathrm{S}_{x} \mathrm{O}_{6}{ }^{2-}$ from the AG2-X8 resin. The AS4A-SC column used on the IC can not be used with acid concentrations over $1 \mathrm{M}$; thus, any sample aliquots will have to be diluted to below $1 \mathrm{M} .9 \mathrm{M} \mathrm{HCl}$ was found to be up to $90 \%$ efficient in the removal of $\mathrm{S}_{x} \mathrm{O}_{6}{ }^{2-}$. Judicious distribution of eluted aliquots can lower the detection limit for $\mathrm{S}_{x} \mathrm{O}_{6}{ }^{2-}$, but the 10 -fold dilution required for IC analysis (due to limits of sample acidity for the column) of $\mathrm{S}_{x} \mathrm{O}_{6}{ }^{2-}$ makes it necessary.

Tetrathionate can also be eluted from the AG2-8X resin using $4 \mathrm{M} \mathrm{KCl}$. The results of this test are presented in Fig. 5. An acidified tetrathionate solution ( $\mathrm{pH}$ 0.5) was passed through an AG2-8X column. Fig. 5A shows the tetrathionate solution before it was loaded onto the column. Fig. 5B shows the ion chromatogram for the tetrathionate solution after it has passed through the column. It is clear from Fig. 5B that all of the tetrathionate is retained. Fig. 5C shows the $4 \mathrm{M} \mathrm{KCl}$ elution, which is dominated by tetrathionate but also contains some trithionate. Trithionate is likely a product of a rearrangement reaction which would be important below $\mathrm{pH} 0.5 .{ }^{75}$ About $90 \%$ of the initial tetrathionate was recovered in this laboratory test. On the basis of these results, we recommend that the elution of the polythionate fraction on the AG2-X8 fraction be carried out with $4 \mathrm{M} \mathrm{KCl}$, rather than $9 \mathrm{M} \mathrm{HCl}$. The $4 \mathrm{M} \mathrm{KCl}$ eluent should also be acidified to approximately $0.01 \mathrm{M} \mathrm{HCl}$ in order to better preserve the polythionates in solution before analysis. It is possible that higher polythionates cannot be recovered with a $4 \mathrm{M} \mathrm{KCl} \mathrm{eluent,}$ because higher polythionates are expected to be more strongly retained then tetrathionate. However, tetrathionate is typically one of the most abundant, if not dominant, $\mathrm{S}_{x} \mathrm{O}_{6}{ }^{2-}$ species in natural waters. If necessary, the $4 \mathrm{M} \mathrm{KCl}$ extraction can be followed with a $9 \mathrm{M} \mathrm{HCl}$ extraction to recover higher polythionates. If the $4 \mathrm{M} \mathrm{KCl}$ elution does not yield any tetrathionate, higher polythionates will likely not be measurable. Hence, there is no need to work with $9 \mathrm{M} \mathrm{HCl}$, which requires a great deal of caution.

\section{Field testing}

Field testing of the AG1-X8 resin was conducted at Yellowstone National Park in the summer of 1997 at 5 different hydrothermal pools. Water samples were also collected at these pools and analyzed on-site by IC using the U.S. Geological Survey mobile lab and at SUNY-Stony Brook within two to three weeks after collection. Comparison of thiosulfate results from on-site IC analysis and IC analysis of AG1-X8 resin column elutions at SUNY-Stony Brook indicates 96 to $100 \%$ agreement for three pools (Cinder Pool, Cistern, and an unnamed pool near Cistern) and 76 and $63 \%$ agreement for two pools (Sulfur Dust and Frying Pan). The poor agreement for the last two pools was likely not due to overloading of the anion-exchange resin columns (which should not have become saturated from the anion chemistry reported in $\mathrm{Xu}$ et $a .^{12}$ ). It is possible that the solution was passed through the columns at too fast a rate for complete binding of the anions. It is important to note that complete binding depends on both the rate and total concentration of anions passed over any volume of resin. The number of anions cannot exceed the total number of binding sites and they must have sufficient time to bind and become immobilized on the resin. Although polythionates were detected at Cinder Pool in the summer of 1997, the AG1-X8 resin exhibited too high a binding capacity with respect to polythionates for those species to be extracted from the resin (Table 1).

Field testing of the AG2-X8 resin was conducted at several hydrothermal pools in Yellowstone National Park in September, 1998. Water samples were collected at pools in Yellowstone National Park and analyzed on-site by IC using the U.S. Geological Survey mobile lab and at SUNY-Stony Brook within two weeks after collection. Sample resin columns were analyzed 1-2 weeks after they were loaded in the field, demonstrating the resin's ability to stabilize the sulfoxyanions in time.

Comparison of thiosulfate results from on-site IC analysis and IC analysis of AG2-X8 resin column elutions at SUNYStony Brook indicates agreement between 87 and $96 \%$ for 5 samples from pools in the Norris Geyser Basin (Fig. 6). Cinder Pool (in the Norris Geyser basin) was sampled in 2 different locations (outer and inner sections of the pool), and 2 samples in each location were analyzed using the resin columns and the on-site IC. The 4 resin column samples were eluted at SUNYStony Brook and analyzed for thiosulfate by IC, resulting in an average concentration of $50.7 \mu \mathrm{m}$, a range of 48.1 to $52.2 \mu \mathrm{m}$, and a standard deviation of $1.7 \mu \mathrm{m}$. No polythionates were detected in Cinder Pool in the summer of 1998 on site, and no polythionates were detected samples taken at the site in 1998 using the AG2-X8 resin columns.

\section{Example application}

The AG2-X8 resin also was used at Green Lake, a meromictic glacial lake located at Green Lake State Park in Fayetteville, New York during the summer of 1998. Green Lake is a stratified lake, with a chemocline at about 20 meters depth. The

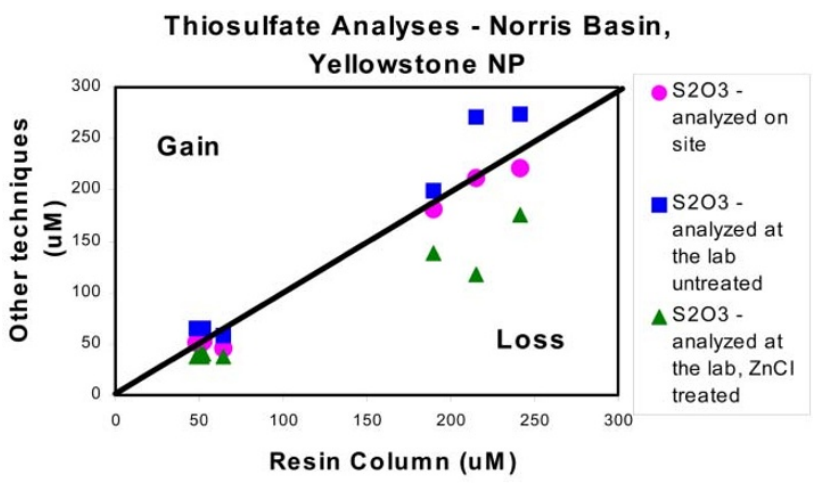

Fig. 6 Comparison of results for three techniques used for thiosulfate analyses for five thermal springs in the Norris Geyser Basin at Yellowstone National Park in September, 1998. 
Table 3 Results from Green Lake, Fayetteville, NY

\begin{tabular}{lclc}
\hline $\begin{array}{l}\text { Sample } \\
\text { depth/m }\end{array}$ & $\begin{array}{l}\mathrm{H}_{2} \mathrm{~S} / \\
\mu \mathrm{mol} \mathrm{L}\end{array}$ & $\begin{array}{l}\mathrm{SO}_{4}{ }^{2-} / \\
\mu \mathrm{mol} \mathrm{L}^{-1}\end{array}$ & $\begin{array}{l}\mathrm{S}_{2} \mathrm{O}_{3}{ }^{2-} / \\
\mu \mathrm{mol} \mathrm{L} \mathrm{L}^{-1}\end{array}$ \\
\hline 15 & 0.7 & 568.7 & 0 \\
20 & 10.0 & 680.5 & 0 \\
22 & 343.5 & 690.8 & 22.0 \\
24 & 406.6 & 684.7 & 0 \\
30 & 472.7 & 682.0 & 13.6 \\
\hline
\end{tabular}

chemocline separates an aerated surface water layer from a deep anoxic water layer. A $1 \mathrm{~m}$ thick transition at the chemocline supports a pink microbial community ${ }^{76}$ and contains up to $22 \mu \mathrm{mol} \mathrm{L}{ }^{-1}$ thiosulfate (Table 3 ). Using a depth sampler, water was brought up from above, below, and within this transition layer. Each sample was loaded onto an AG2-X8 resin column, taken back to SUNY-Stony Brook, and analyzed for thiosulfate and polythionates by IC after 2-5 days. Hydrogen sulfide concentrations were determined on site (HACH method 8131). No attempt was made to determine sulfur present as FeS, elemental sulfur, polysulfide, or other forms of sulfur that may explain the apparent mass balance fluctuations in the profile.

\section{Conclusions}

Sampling of metastable sulfoxyanions may be reliably and reproducibly accomplished under a variety of field conditions using Bio-RadiII AG2-X8 anion-exchange resin columns. Using a series of eluents of increasing $\mathrm{Cl}$ concentration, sulfate, thiosulfate, and polythionates can be eluted sequentially. Recoveries of $87-100 \%$ for known concentrations of thiosulfate and polythionate in laboratory and field tests indicates that the method is more reliable over time than other methods of sample preservation. Laboratory and field testing over a significant range of temperature and acidity indicates this technique may be readily applied to nearly any environment; use of AG2-X8 resin columns is being planned for use in both highly acidic mine waste waters and in hot, highly acidic crater lake waters. The resin method presented here is particularly useful for the sampling of sulfide-rich waters. Continued reaction of dissolved hydrogen sulfide and molecular oxygen changes the sulfoxyanion concentrations. Field tests have shown that adding of zinc or cadmium to precipitate the sulfide does not prevent these reactions from taking place. In fact, the metal sulfides may catalyze certain reactions.

The ruggedness, as well as small size and weight of the plastic columns facilitates handling in the field. Furthermore, it is possible to ship columns and elute the columns several weeks after sampling.

\section{Acknowledgements}

The U.S. National Park Service Staff at Yellowstone National Park is thanked for their help during the field studies. The New York State Department of Parks is thanked for their assistance at Green Lake, NY. The participation of the Stony Brook group in this project was supported through grants from NSF-EAR to M. Schoonen. A few of the laboratory tests were conducted in the Department of Geology and Geophysics, University of Wisconsin-Madison.

\section{References}

1 M. A. A. Schoonen, Mechanisms of pyrite and marcasite formation from solution between 25 and 300C, in Geology, Pennsylvania State University, University Park, 1989.

2 M. A. Williamson and J. D. Rimstidt, Correlation between structure and thermodynamic properties of aqueous sulfur species, Geochim. Cosmochim. Acta, 1992, 56, 3867-3880.
3 H. L. Barnes, Solubilities of ore minerals, in Geochemistry of Hydrothermal Ore Deposits, ed. H. L. Barnes, John Wiley \& Sons, New York, 1979, p. 404-460.

4 J. Boulegue, Metastable Sulfur Species and Trace-Metals (Mn, Fe, $\mathrm{Cu}, \mathrm{Zn}, \mathrm{Cd}, \mathrm{Pb})$ in Hot Brines from French Dogger, Am. J. Sci., 1978, 278(10), 1394-1411

5 J. G. Webster, Thiosulfate in surficial geothermal waters, North Island, New Zealand, Appl. Geochem., 1987, 2(5-6), 579-584.

6 J. G. Webster, An analytical scheme for the determination of sulfide, polysulfide, thiosulfate, sulfite and polythionate concentrations, DSIR, Petone, New Zealand, 1989.

7 E. Veldeman, L. Vantdack, R. Gijbels and E. N. Pentcheva, Sulfur Species and Associated Trace-Elements in South-West Bulgarian Thermal Waters, Appl. Geochem., 1991, 6(1), 49-62.

8 A. Pentecost, The Microbial Ecology of Some Italian Hot-Spring Travertines, Microbios, 1995, 81(326), 45-58.

9 E. T. Allen, The hot springs of the Yellowstone National Park, Carnegie Inst. Washington News Serv. Bull. School Ed., 1936, 4(1), $1-20$.

10 E. T. Allen and A. L. Day, in Hot Springs of the Yellowstone National Park. Microscopic examinations by Herbert Eugene Merwin, Carnegie Institution of Washington, Washington, DC, 1935, vol. 466, p. 525.

11 Y. Xu, M. A. A. Schoonen, D. K. Nordstrom, K. M. Cunningham and J. W. Ball, Sulfur geochemistry of hydrothermal waters in Yellowstone National Park, Wyoming, USA. II. Formation and decomposition of thiosulfate and polythionate in Cinder Pool, J. Volcanol. Geotherm. Res., 2000, 97(1-4), 407-423.

12 Y. Xu, M. A. A. Schoonen, D. K. Nordstrom, K. M. Cunningham and J. W. Ball, Sulfur geochemistry of hydrothermal waters in Yellowstone National Park: I. The origin of thiosulfate in hot spring waters, Geochim. Cosmochim. Acta, 1998, 62(23-24), 3729-3743.

13 B. Takano, S. Ohsawa and R. B. Glover, Surveillance of Ruapehu Crater Lake, New-Zealand, by Aqueous Polythionates, J. Volcanol. Geotherm. Res., 1994, 60(1), 29-57.

14 E. Cherbuliez and R. Weibel, Sur l'hydrolyse du soufre par l'eau au-dessous de 100, Helv. Acta, 1936, 29, 796-806.

15 S. R. Wilson, Natural occurrence of polythionic acids, Nature, 1941, 148, 502-503.

$16 \mathrm{~K}$. Y. Chen and J. C. Morris, Kinetics of oxidation of aqueous sulfide by $\mathrm{O}_{2}$, Environ. Sci. Technol., 1972, 6, 529-537.

17 D. J. O'Brien and F. B. Birkner, Kinetics of oxygenation of reduced sulfur species in aqueous solutions, Environ. Sci. Technol., 1977, 11, 1114-1120.

18 J. Z. Zhang and F. J. Millero, The Products from the Oxidation of $\mathrm{H}_{2} \mathrm{~S}$ in Seawater, Geochim. Cosmochim. Acta, 1993, 57(8), 1705 1718 .

19 J.-Z. Zhang, The chemistry of the anoxic waters in the Cariaco Trench, Deep-Sea Res., 1993, 40(5), 1023-1041.

20 J. Z. Zhang and F. J. Millero, Kinetics of Oxidation of HydrogenSulfide in Natural-Waters, in Environmental Geochemistry of Sulfide Oxidation, ed. C. N. Alpers and D. W. Blowes, American Chemical Society, Washington, DC, 1994, pp. 393-409.

21 J. Z. Zhang and F. J. Millero, Investigation of Metal Sulfide Complexes in Sea-Water Using Cathodic Stripping Square-Wave Voltammetry, Anal. Chim. Acta, 1994, 284(3), 497-504.

$22 \mathrm{Y} . \mathrm{Xu}$ and M. A. A. Schoonen, The stability of thiosulfate in the presence of pyrite in low-temperature aqueous solutions, Geochim. Cosmochim. Acta, 1995, 59(22), 4605-4622.

23 Y. Xu, M. A. A. Schoonen, D. K. Nordstrom, K. M. Cunningham and J. W. Ball, Formation, reactivity, stability, and analysis of thiosulfate and polythionates in hydrothermal waters, in Crater Lakes, Terrestrial Degassing and Hyper-acid Fluids in the Environment, Crater Lake, Oregon, AGU-Chapman Conference, 1996.

24 D. E. Canfield and D. J. D. Marais, Aerobic sulfate reduction in microbial mats, Science, 1991, 251(5000), 1471-1473.

25 B. B. Jorgensen and F. Bak, Pathways and microbiology of thiosulfate transformations and sulfate reduction in a marine sediment (Kattegat, Denmark), Appl. Environ. Microbiol., 1991, 57(3), 847-856.

26 L. Elsgaard, M. F. Isaksen, B. B. Jorgensen, A. Alayse and H. W. Jannasch, Microbial sulfate reduction in deep-sea sediments at the Guaymas Basin hydrothermal vent area: Influence of temperature and substrates, Geochim. Cosmochim. Acta, 1994, 58(16), 3335-3343.

27 B. B. Jorgensen, Sulfate reduction and thiosulfate transformations in a cyanobacterial mat during a diel oxygen cycle, FEMS Microbiol. Ecol., 1994, 13(4), 303-312.

28 M. B. Goldhaber and W. L. Orr, Kinetic controls on thermochemical sulfate reduction as a source of sedimentary $\mathrm{H}_{2} \mathrm{~S}$, in 
Geochemical Transformations of Sedimentary Sulfur, ed. M. A. Vairavamurthy and M. A. A. Schoonen, American Chemical Society, Washington, DC, 1995, pp. 412-425.

29 I. Hutcheon, H. R. Krouse and H. J. Abercombie, Controls on the origin and distribution of elemental sulfur, $\mathrm{H}_{2} \mathrm{~S}$, and $\mathrm{CO}_{2}$ in Paleozoic hydrocarbon reservoirs in Western Canada, in Geochemical Transformations of Sedimentary Sulfur, ed. M. A. Vairavamurthy and M. A. A. Schoonen, American Chemical Society, Washington, DC, 1995, pp. 426-438.

30 H. G. Machel, H. R. Krouse and R. Sassen, Products and Distinguishing Criteria of Bacterial and Thermochemical Sulfate Reduction, Appl. Geochem., 1995, 10(4), 373-389.

31 H. G. Machel, H. R. Krouse, L. R. Riciputi and D. R. Cole, Devonian Nisku sour gas play, Canada: A unique natural laboratory for study of thermochemical sulfate reduction, in Geochemical Transformations of Sedimentary Sulfur, 1995, pp. 439-454

32 B. B. Jorgensen, The Sulfur Cycle of Fresh-Water Sediments Role of Thiosulfate, Limnol. Oceanogr., 1990, 35(6), 1329-1342.

33 B. B. Jorgensen, A Thiosulfate Shunt in the Sulfur Cycle of Marine-Sediments, Science, 1990, 249(4965), 152-154

34 B. Takano, Correlation of Volcanic Activity with Sulfur Oxyanion Speciation in a Crater Lake, Science, 1987, 235(4796), 1633-1635.

35 B. Takano and K. Watanuki, Monitoring of Volcanic-Eruptions at Yugama Crater Lake by Aqueous Sulfur Oxyanions, J. Volcanol. Geotherm. Res., 1990, 40(1), 71-87.

36 B. Takano, H. Saitoh and E. Takano, Geochemical Implications of Subaqueous Molten Sulfur at Yugama Crater Lake, KusatsuShirane Volcano, Japan, Geochem. J., 1994, 28(3), 199-216.

37 B. Takano and K. Watanuki, Monitoring of volcanic eruptions at Yugama crater lake by aqueous sulfur oxyanions, J. Volcanol. Geotherm. Res., 1990, 40, 71-87.

38 M. Benedetti and J. Boulegue, Mechanism of gold transfer and deposition in a supergene environment, Geochim. Cosmochim. Acta, 1991, 55, 1539-1547.

39 M. L. Machesky, W. O. Andrade and A. W. Rose, Adsorption of gold(III)-chloride and gold(I)-thiosulfate anions by goethite, Geochim. Cosmochim. Acta, 1991, 55, 769-776.

40 B. M. Mitsyuk, A. G. Mironov, A. M. Plyusin and N. V. Belomestrova, Gold uptake by silica from dilute chloride, thiosulfate, and ammonical solutions, Geochem. Int., 1991, 28, 852-859

41 E. Y. Anthony and P. A. Williams, Thiosulfate complexing of platinum group elements, in Environmental geochemistry of sulfide oxidation, ed. C. A. Alpers and D. Blowes, 1994, American Chemical Society, Washington, DC, pp. 551-560.

42 H. Kucha, W. Prohaska and E. P. Stumpfl, Deposition and transport of gold by thiosulfates, Veitsch, Austria, Mineral. Mag., 1995, 59, 253-258.

43 F. Uyama, H. Chiba, M. Kasakabe and H. Sakai, Sulfur isotope exchange reactions in the aqueous system: thiosulfate-sulfidesulfate at hydrothermal temperature, Geochem. J., 1985, 19, 301315.

44 H. Ohmoto and A. C. Lasaga, Kinetics of reactions between aqueous sulfates and sulfides in hydrothermal systems, Geochim. Cosmochim. Acta, 1982, 46, 1727-1745.

45 P. T. Visscher, R. A. Prins and H. van Gemerden, Rates of sulfate reduction and thiosulfate consumption in a marine microbial mat, FEMS Microbiol. Ecol., 1992, 86, 283-294.

46 P. T. Visscher and H. van Gemerden, Sulfur cycling in laminated marine microbial ecosystems, in Biogeochemistry of global change, ed. C. R. Ormeland, Chapman Hill, 1993, pp. 672-690.

47 H. Fossing, ${ }^{35}$ S-radiolabeling to probe biogeochemical cycling of sulfur, in Geochemical Transformations of Sedimentary Sulfur. ed. M. A. Vairavamurthy and M. A. A. Schoonen, 1995, American Chemical Society, Washington, DC, pp. 348-364.

48 D. V. Vivit, J. W. Ball and E. A. Jenne, Specific-ion electrode determinations of sulfide preconcentrated from San Fransico Bay waters, Environ. Geol. Water Sci., 1984, 6, 79-90.

49 S. S. Lindsay and M. J. Baedecker, Determination of aqueous sulfide in contaminated and natural water using the methylene blue method, in Regional Ground Water Quality, ed. W. A. Alley, 1993, van Nordstrand Reinhold, pp. 349-356.

50 R. Makhija and A. Hitchen, Titrimetric determination of sulfate, thiosulfate and polythionates in mining effluents, Anal. Chim. Acta, 1979, 105, 375-382

51 B. Takano, M. A. McKibben and H. L. Barnes, LiquidChromatographic Separation and Polarographic Determination of Aqueous Polythionates and Thiosulfate, Anal. Chem., 1984, 56(9), 1594-1600.
52 B. Takano and K. Watanuki, Quenching and Liquid-Chromatographic Determination of Polythionates in Natural-Water, Talanta, 1988, 35(11), 847-854.

53 A. Hitchen and C. W. Smith, A review of analytical methods for the dermination of polythionates, thiosulfate, sulfite, and sulfide in mining effluents, CANMET, Ottawa, Canada, 1976.

54 R. A. Perry, R. Atkinson and J. N. Pitts, Rate constants for the reactions $\mathrm{OH}+\mathrm{H}_{2} \mathrm{~S} \rightarrow \mathrm{H}_{2} \mathrm{O}+\mathrm{HS}$ and $\mathrm{OH}+\mathrm{NH}_{3} \rightarrow \mathrm{H}_{2} \mathrm{O}+\mathrm{NH}_{2}$ over the temperature range 297-427 K, J. Phys. Chem., 1976, 64, 3237-3239.

55 P. T. Visscher, C. W. Culbertson and R. S. Oremland, Degradation of trifluoracetate in oxic and anoxic sediments, Nature, 1994, 369, 729-731

56 J. W. O’Reilly, G. W. Dicinoski, M. J. Shaw and P. R. Haddad, Chromatographic and electrophoretic separation of inorganic sulfur and sulfur-oxygen species, Anal. Chim. Acta, 2001, 432(2), 165-192.

57 R. D. Vetter, P. A. Matrai, B. Javor and J. O'Brien, Reduced sulfur compounds in the marine environment, in Biogenic sulfur in the environment, ed. E. S. Saltzman and W. J. Cooper, American Chemical Society, Washington, DC, 1989

58 A. F. White, M. L. Peterson and R. D. Solbau, Measurement and Interpretation of Low-Levels of Dissolved-Oxygen in GroundWater, Ground Water, 1990, 28(4), 584-590.

59 M. J. Baedecker and M. Cozzarelli, The determination and fate of unstable constituents of contaminated groundwater, in Groundwater contamination and analysis at hazardous waste sites, ed S. Lesage and R. E. Jackson, Marcel Dekker, New York, 1992, pp. 425-461.

60 K. M. Cunningham, W. G. Wright, D. K. Nordstrom, J. W. Ball, M. A. A. Schoonen and Y. Xu, Water-quality data for Doughty Springs, Delta County, Colorado, 1903-1994, with emphasis on sulfur redox species, U.S. Geological Survey, Denver, 1996.

61 F. C. Canney and D. B. Hawkins, Field application of ion-exchange resins in hydrogeochemical prospecting, in U.S. Geological Survey Professional Paper, Report: P 0400-B, U.S. Geological Survey, Reston, 1960, pp. B89-B90.

62 W. F. McKenzie and A. H. Truesdell, Geothermal reservoir temperatures estimates from the oxygen isotope compositions of dissolved sulfate and water from hot springs and shallow drillholes, Geothermics, 1977, 5, 51-61.

63 H. Sakai, Sulfate-water isotope thermometry applied to geothermal systems, Geothermics, 1977, 5, 67-74.

64 W. H. Ficklin, Separation of Arsenic(III) and Arsenic(v) in Ground Waters by Ion-Exchange, Talanta, 1983, 30(5), 371-373.

65 A. Iguchi, The Separation of Polythionates with Anion-Exchange Resins, Bull. Chem. Soc. Jpn., 1958, 31(5), 597-600.

66 A. Iguchi, The Separation of Sulfate, Sulfite, Thiosulfate and Sulfide Ions with Anion-Exchange Resins, Bull. Chem. Soc. Jpn., 1958, 31(5), 600-605.

67 F. H. Pollard, G. Nickless and R. B. Glover, Chromatographic studies on sulfur compounds Part V: A study to seperate thiosulfate, sulfite, and the lower polythionates by anion-exchange chromatography, J. Chromatogr., 1964, 15, 533-537.

68 A. W. Wolkoff and R. H. Larose, Seperation and detection of low concentrations of polythionates by high speed anion exchange liquid chromatography, Anal. Chem., 1975, 47(7), 1003-1008.

69 H. F. Aly, M. M. Abdel-Hamid and A. A. Abdel Rassoul, Gradient chromatographic elution of sulfur anions, J. Radioanal. Chem., 1977, 40, 65-68.

70 A. Y. Salem and S. A. R. Rahim, Ion exchange process for removal of sulfur species from sulfuretted waters, J. Iraqi Chem. Soc., 1976, 1, 39-45.

71 Guide to Ion Exchange, BioRad, Hercules, CA, 1999.

72 H. Zou, Z. Jia, Y. Zhang and P. Lu, Separation of aqueous polythionates by reversed-phase ion-pair liquid chromatography with suppressor-conductivity detection, Anal. Chim. Acta, 1993 284, 59-65.

73 D. P. Kelly and A. P. Wood, Synthesis and determination of thiosulfate and polythionates, in Methods in Enzymology Volume 243: Inorganic microbial sulfur metabolism, ed. H. D. J. Peck and J. LeGall, Academic Press, New York, 1994, pp. 475-501.

74 D. P. Kelly, L. A. Chambers and P. A. Trudinger, Cyanolysis and spectrometric estimation of trithionate in mixtures with thiosulfate and tetrathionate, Anal. Chim. Acta, 1969, 41, 898-901.

75 G. K. Druschel, R. J. Hamers and J. F. Banfield, Kinetics and mechanism of polythionate oxidation to sulfate at low $\mathrm{pH}$ by $\mathrm{O}_{2}$ and $\mathrm{Fe}^{3+}$, Geochim. Cosmochim. Acta, in press.

76 N. S. Suits and R. T. Wilkin, Pyrite formation in the water column and sediments of a meromictic lake, Geology, 1998, 26(12), 10991102 . 